\title{
High-Frequency Oscillatory Ventilation Versus Intermittent Mandatory Ventilation: Early Hemodynamic Effects in the Premature Baboon with Hyaline Membrane Disease ${ }^{1}$
}

\author{
JOHN P. KINSELLA, DALE R. GERSTMANN, REESE H. CLARK, DONALD M. NULL, JR., \\ W. ROBERT MORROW, A. FLORENTINA TAYLOR, AND ROBERT A. deLEMOS \\ Department of Pediatrics, Wilford Hall U.S.A.F. Medical Center, San Antonio, Texas 78236 [J.P.K., R.H.C., \\ D.M.N., W.R.M.J and Department of Physiology and Medicine, Southwest Foundation for Biomedical Research, \\ San Antonio, Texas 78228 [D.R.G., A.F.T., R.A.D.]
}

\begin{abstract}
We studied the hemodynamic consequences during the first $24 \mathrm{~h}$ of life in premature baboons (140 d) with hyaline membrane disease that were treated with high-frequency oscillatory ventilation (HFOV) or conventional intermittent mandatory ventilation (IMV). Cardiac output and organ blood flow were measured at three timepoints using the radiolabeled microsphere technique. Seven of seven HFOV and six of eight IMV animals survived the 24-h period. By design, initial mean airway pressure $\left(\overline{\mathrm{P}}_{\mathrm{aw}}\right)$ was higher in the HFOV group $(p<0.01)$. HFOV $\overline{\mathrm{P}}_{\mathrm{aw}}$ was progressively reduced during the study period because of improving oxygenation as measured by the arterial to alveolar oxygen ratio. In contrast, it was necessary to increase $\overline{\mathrm{P}}_{\mathrm{aw}}$ in the IMV animals to maintain the arterial to alveolar oxygen ratio. By $23 \mathrm{~h}$, the IMV group required higher $\overline{\mathbf{P}}_{\mathrm{aw}}$ than the HFOV group $(p<0.05)$ and had a lower arterial to alveolar oxygen ratio $(p<0.05)$. We found no significant differences in left ventricular output, effective systemic flow, organ blood flow, or central venous pressure between the two groups at 3,8 , or $23 \mathrm{~h}$. The HFOV strategy used in our study resulted in significant improvement in oxygenation during the initial $24 \mathrm{~h}$ of treatment without adverse effect on left ventricular output, cerebral blood flow, or central venous pressure. We conclude that when appropriate changes in $\overline{\mathbf{P}}_{\mathrm{aw}}$ are made during HFOV in response to improvement in arterial oxgenation and changes in lung inflation as assessed by chest radiographs HFOV can be achieved without depressing cardiovascular dynamics more than during conventional therapy with IMV. (Pediatr Res 29: 160-166, 1991)
\end{abstract}

\section{Abbreviations}

CVP, central venous pressure

$\mathrm{FiO}_{2}$, fraction of inspired oxygen

HFOV, high-frequency oscillatory ventilation

HMD, hyaline membrane disease

IMV, intermittent mandatory ventilation

LVO, left ventricular output

$\overline{\mathbf{P}}_{\mathrm{aw}}$, mean airway pressure

PEEP, positive end expiratory pressure

PIP, peak inspiratory pressure

Received March 3, 1990; accepted October 3, 1990.

Correspondence: John P. Kinsella, M.D., 3304 S. Quintero St., Aurora, CO 80013.

Supported by SCOR Grant no. HL36536 from the National Institutes of Health and Grant no. 88G-604 from the American Heart Association-Texas Affiliate.

1 The opinions expressed are those of the authors and do not necessarily reflect those of the U.S.A.F. or the Department of Defense.
$\dot{\mathrm{Q}}_{\mathrm{s}}$ eff, effective systemic flow

$\mathbf{L} \mathbf{V}_{\max }$, lung volume at maximum distending pressure

$\mathrm{PaO}_{2}$, arterial oxygen partial pressure

$\mathrm{PaCO}_{2}$, arterial carbon dioxide partial pressure

$\mathrm{Pa} / \mathrm{AO}_{2}$, arterial to alveolar oxygen ratio

$\mathrm{P}-\mathrm{V}$, pressure-volume

PDA, patent ductus arteriosus

CPAP, continuous positive airway pressure

Studies of HFOV in the treatment of HMD have yielded conflicting results. Some observers have hypothesized that critical differences in strategy used in the application of HFOV account for the apparent inconsistencies among studies $(1,2)$. Investigators using HFOV with a strategy designed to recruit and maintain adequate alveolar/saccular volume have shown dramatic beneficial effects in humans and experimental animals with HMD (3-5). In other studies, when the ventilation strategy was aimed at maintaining lower ventilator pressures, responses to HFOV were not as dramatic (6-8).

We have recently shown that early institution of HFOV at a high $\overline{\mathrm{P}}_{\mathrm{aw}}$ protected the surfactant-deficient premature baboon from changes in gas exchange, lung mechanics, and morphology typical of HMD in this model (9). However, there was indirect evidence in these studies that cardiac output and systemic perfusion were adversely affected, most likely as a result of inadvertent lung overdistention after effective alveolar recruitment and the maintenance of a relatively high $\overline{\mathrm{P}}_{\mathrm{aw}}$. Traverse et al. (10) noted that in cats cardiac output decreased and pulmonary vascular resistance increased with increasing mean airway pressure during HFOV. Although the response was diminished in animals with decreased respiratory system compliance, it was not eliminated. Similar findings in swine during conventional ventilation and PEEP support the fact that airway pressure effects on cardiovascular hemodynamics are not blunted by low pulmonary compliance if the poorly and normally compliant lungs are equally inflated (11). There is concern that the use of HFOV in the premature infant may contribute to or accentuate impairment of cardiovascular performance $(6,12)$.

To test the hypothesis that in the premature infant HFOV may predispose to such effects to a greater extent than does conventional mechanical ventilation (IMV), we have investigated the hemodynamic consequences of ventilator strategies for HFOV and IMV that emphasize the appropriate weaning of $\overline{\mathrm{P}}_{\mathrm{aw}}$. These experiments have been performed in the baboon model of HMD using the radiolabeled microsphere technique. 


\section{MATERIALS AND METHODS}

Animal model. Before the start of these experiments, all animal use protocols were reviewed and approved by the Animal Research Committee at the Southwest Foundation for Biomedical Research. Fifteen premature baboons (Papio cynocephalus) were delivered by hysterotomy at $140 \pm 2 \mathrm{~d}$ gestation $(180 \mathrm{~d}=$ term $)$. Gestational ages were determined by matings that were timed by observation of female perineal sex skin changes and confirmed with ultrasound examination at intervals during pregnancy. Before delivery, each animal was assigned to a ventilator treatment group using a system of random numbers.

Instrumentation. All animals were resuscitated with endotracheal intubation and anesthetized with intramuscular ketamine hydrochloride and s.c. xylocaine. Endotracheal tube position was determined radiographically. Vascular access was obtained at four separate sites. A 1.2-mm diameter polyvinyl umbilical artery catheter was placed with the end of the catheter $1-2 \mathrm{~cm}$ above the bifurcation of the aorta. The umbilical artery catheter was used for withdrawal of an arterial reference sample during each microsphere injection. A 560- $\mu \mathrm{m}$ diameter, 19-mm long catheter was placed by cutdown in the right brachial artery for continuous monitoring of blood pressure. A femoral vein was cannulated with 580- $\mu \mathrm{m}$ diameter tubing (Intramedic; Becton Dickinson, Parsippany, NJ) and the tip of the tubing was advanced to the right atrium. The left carotid artery was cannulated with a specially designed catheter consisting of a $6-\mathrm{cm}$ segment of 280 $\mu \mathrm{m}$ diameter tubing affixed to $20 \mathrm{~cm}$ of $580-\mu \mathrm{m}$ tubing. This design was necessary to provide the smallest diameter catheter within the aortic valve while keeping total catheter resistance low. This catheter was advanced to the left ventricle for microsphere injections. Catheter position in the left ventricle was verified using echocardiography, radiographs during contrast injection, and continuous monitoring of left ventricular pressure.

Mechanical ventilation. Animals were ventilated by either IMV or HFOV instituted immediately after delivery using a strategy to maintain $\mathrm{PaCO}_{2}$ between 4.7 and $7.3 \mathrm{kPa}$ and $\mathrm{PaO}_{2}$ between 6.7 and $10.7 \mathrm{kPa}$, and to maximally wean inspiratory oxygen concentration $\left(\mathrm{FiO}_{2}\right)$. IMV animals $(n=8)$ were ventilated with a time-cycled, pressure-limited infant ventilator (Bear $\mathrm{Cub}$, Bournes Inc., Riverside, CA) from the time of intubation. $\mathrm{PaCO}_{2}$ was maintained within the target range by varying ventilatory frequency (initial $0.5 \mathrm{~Hz}$, maximum $1 \mathrm{~Hz}$ ) and tidal volume, with the inspiratory duration between 0.5 and $0.6 \mathrm{~s}$. Based on previous experience, where higher ventilator pressures were associated with an extremely high incidence of airleak (13), PIP was initially set to maintain $\overline{\mathrm{P}}_{\mathrm{aw}}$ at $1.2-1.3 \mathrm{kPa}$. To optimize lung volume and oxygenation, initial PEEP was set at $0.6-0.7 \mathrm{kPa}$ and $\mathrm{FiO}_{2}$ was begun at 1.0. If the $\mathrm{PaO}_{2}$ was above $10.7 \mathrm{kPa}, \mathrm{FiO}_{2}$ was decreased incrementally. If $\mathrm{FiO}_{2}$ was above 0.7 with the $\mathrm{PaO}_{2}$ within protocol guidelines, or the $\mathrm{PaO}_{2}$ was below $8.0 \mathrm{kPa}$ in $\mathrm{FiO}_{2} 1.0, \overline{\mathrm{P}}_{\mathrm{aw}}$ was increased by increments of $0.1 \mathrm{kPa}$. When ventilation was adequate, changes in $\overline{\mathrm{P}}_{\mathrm{aw}}$ were accomplished by adjustment of PEEP, if both ventilation and oxygenation were low, PIP was increased.

Immediately after intubation, HFOV animals $(n=7)$ were given two positive pressure insufflations at $3.0 \mathrm{kPa}$ for $20 \mathrm{~s}$. These animals were then placed on a piston oscillator powered by a linear motor (model 3200; Sensor-Medics, Dayton, $\mathrm{OH}$ ). Initially, $\overline{\mathrm{P}}_{\mathrm{aw}}$ was set between 1.8 and $1.9 \mathrm{kPa}$. Oxygenation was optimized by adjustment of $\overline{\mathrm{P}}_{\mathrm{aw}}$ with the primary objective to decrease $\mathrm{FiO}_{2}$ below 0.5 as rapidly as possible. $\overline{\mathrm{P}}_{\mathrm{aw}}$ was decreased by $0.2 \mathrm{kPa}$ when the $\mathrm{FiO}_{2}$ reached 0.5 with $\mathrm{PaO}_{2}$ within protocol parameters. Assuming that continued improvement in oxygenation resulted from expansion of airless lung as demonstrated in previous studies using this strategy $(2), \overline{\mathrm{P}}_{\mathrm{aw}}$ was subsequently reduced after evaluation of lung inflation on chest radiographs. This measure of relative lung volume was assessed by noting changes in radiolucency and changes in the level of the hemidiaphragms in relation to the infracardiac border on sequential films. Ventilation $\left(\mathrm{PaCO}_{2}\right)$ was optimized by adjustment of oscillatory amplitude.

Details of routine nursery management are similar to those previously reported $(3,13)$. In brief, a servo-controlled overhead radiant warmer was used to maintain core temperature, and i.v. crystalloid solution was administered at volumes of $150-200$ $\mathrm{mL} /(\mathrm{kg} \cdot \mathrm{d})$ to maintain urine output $>24 \mathrm{~mL} /(\mathrm{kg} \cdot \mathrm{d})$. All animals were sedated with ketamine and diazepam, pharmacologically paralyzed with pancuronium bromide, and, with the exception of the mode of ventilation, were managed identically throughout the 24-h experimental period.

Blood pressure, CVP, heart rate, respiratory rate, rectal temperature, arterial blood gases, and ventilator settings were recorded hourly. Arterial blood gases were measured with an AVL blood gas analyzer (AVL Scientific Corp., Roswell, GA) calibrated within the physiologic range. $\mathrm{Pa} / \mathrm{AO}_{2}$ and an index of oxygenation were calculated. The index of oxygenation corrected $\mathrm{Pa} / \mathrm{AO}_{2}$ for $\overline{\mathrm{P}}_{\mathrm{aw}}$ as $\left(\mathrm{Pa} / \mathrm{AO}_{2} \times 10 / \overline{\mathrm{P}}_{\mathrm{aw}}\right)$. Portable chest radiographs were obtained immediately after resuscitation, at each microsphere injection timepoint, and as clinically indicated during the study period. Ventilator pressures were measured just proximal to the endotracheal tube with a Validyne pressure transducer (DP 45; Validyne, Northridge, CA) with linear calibration to 40 $\mathrm{Hz}$. Ventilation was maintained until the end of the experimental period when all animals were electively killed with an overdose of anesthesia.

Measurements of lung mechanics. At necropsy, a segment of the left upper lobe was weighed, dried, and reweighed for determination of the dry/wet weight ratio and the percent lung water. The entire right lung was weighed and its main stem bronchus cannulated. The lung was then connected to a P-V apparatus as previously described (9). After completing two standard inflations and deflations from 0 to $3.5 \mathrm{kPa}$, the lung was inflated and deflated in stepwise $0.5-\mathrm{kPa}$ pressure increments with a $2-\mathrm{min}$ pause at each pressure to allow for volume equilibration. If volume did not stabilize within the equilibration period, an attempt was made to detect and seal the leak and the study was repeated.

Microsphere method. The principles of microsphere use followed in these experiments are as described by Heymann et al. (14). Modifications of the technique required for adapting the methodology to the premature baboon are described below.

Microspheres of $16.5 \pm 0.1 \mu \mathrm{m}$ (DuPont-New England Nuclear, Wilmington, DE) labeled with ${ }^{57} \mathrm{Co},{ }^{113} \mathrm{Sn}$, and ${ }^{46} \mathrm{Sc}$ were suspended in $154 \mathrm{mmol} / \mathrm{L}$ saline with $76 \mu \mathrm{mol} / \mathrm{L}$ Tween 80 . Each batch of microspheres was initially assessed for spectral distribution, sp act, effect of counter height geometry and coincidence loss at high count rates in a Beckman 8500 (Beckman Instruments, Irvine, CA) three-channel scintillation counter with a 76-mm through-hole NaI crystal. The energy windows used for ${ }^{57} \mathrm{Co},{ }^{113} \mathrm{Sn}$, and ${ }^{46} \mathrm{Sc}$ were $60-160,240-410$, and $700-1100 \mathrm{keV}$, respectively. In preparation for injection, the microsphere vials were vigorously vortexed for $2 \mathrm{~min}$ and placed in an ultrasonicator bath for 5 min to disperse aggregates. Five $\times 10^{4}$ to $8.0 \times$ $10^{4}$ microspheres $(50-100 \mu \mathrm{L})$ were placed in a $10-\mathrm{mL}$ syringe containing a solution of $2.5 \mathrm{mmol} / \mathrm{L}$ dextran $40(4 \mathrm{~mL})$ and fresh heparinized adult baboon donor blood $(0.5 \mathrm{~mL})$. Immediately before injection, the syringe was again agitated on the vortex mixer. The syringe was then attached to the left ventricular catheter and placed on an infusion pump. The injectate solution was infused at a constant rate over $270 \mathrm{~s}$. After the injection was completed, the left ventricular line was flushed with $1.5 \mathrm{~mL}$ of blood to clear the catheter of residual microspheres and to maintain isovolemia. After flushing the Luer stub was replaced. The reference sample was obtained using a withdrawal syringe (Harvard Apparatus Co., Inc., S. Natick, MA) at a constant rate of $17.2 \mu \mathrm{L} / \mathrm{s}$ (approximately $33 \mu \mathrm{L} / \mathrm{kg} \cdot \mathrm{s}$ ) beginning $10 \mathrm{~s}$ before the injection of microspheres and continuing for $90 \mathrm{~s}$ after the injection was completed. Microsphere injections were performed at 3,8 , and $23 \mathrm{~h}$. 
The animals were hemodynamically stable during the microsphere injections. No significant changes were noted in heart rate, arterial blood pressure, or mean aortic velocity by Doppler. The range of microspheres (mean $=981$ ) present in the reference blood samples was $460-2024$, thus allowing a $95 \%$ probability of determining ventricular output to within $10 \%$ of its true value, as described by Buckberg et al. (15). Studies in our lab of the technique described above have shown absence of microsphere aggregates microscopically, even distribution of microspheres in the injectate over the entire injection period, complete clearance of microspheres from the arterial circulation by the end of the reference sample withdrawal, and absence of residual radioactivity in the ventricular catheter after flushing (unpublished data). Evenness of circulatory distribution of injected microspheres was assessed by comparison of paired organ flow (renal). In addition, in five animals, simultaneous right brachial and abdominal aortic reference samples were obtained. Neither paired organ flow nor paired arterial reference sample comparisons differed by greater than $15 \%$ using the left ventricular injection site. Nonentrapment was found to be less than $1 \%$ of injected microspheres when measured with simultaneous right atrial and aortic sampling in two animals.

At necropsy, organs were excised for gamma counting and the carcass was carbonized in an oven at $325^{\circ} \mathrm{C}$ in a manner similar to that described by Hoffman et al. (16). After carbonization, the carcass ash was placed in scintillation vials and also counted.

A computer program was written for interpretation of microsphere scintillation counts using matrix inversion analysis. This process allows for correction of spillover counts from the predetermed regions of interest surrounding each isotope's main photopeaks. The program uses a file containing height geometry calibrations, isotope decay calculations, sp act, and coincidence loss data for each nuclide. The total number of microspheres injected was determined by summing the microsphere content of the carcass and organs. LVO and organ blood flow in $\mathrm{mL} /$ min were calculated using the following equations (16):

$$
\begin{gathered}
\mathrm{LVO}=\mathrm{T}_{\mathrm{m}}\left(\mathrm{R}_{\mathrm{w}} / \mathrm{R}_{\mathrm{m}}\right) \\
\text { Organ blood flow }=\mathrm{O}_{\mathrm{m}}\left(\mathrm{R}_{\mathrm{w}} / \mathrm{R}_{\mathrm{m}}\right)
\end{gathered}
$$

where $T_{m}$ is the total number of microspheres injected; $O_{m}$ is the number of microspheres in the organ of interest; and $R_{m}$ and $R_{w}$ are the number of microspheres and the withdrawal rate of the reference sample, respectively. LVO was then corrected for animal weight and organ blood flow referenced to organ weight.

Statistical analysis. LVO, blood flow distribution, physiologic measurements, ventilator settings, and calculated measurements of gas exchange were compared using two-way analysis of variance for repeated measures. Using the two-way model, ventilator treatment group and time were identified as independent variables and the interaction between them analyzed. Where significant main effects were identified in the analysis of variance for repeated measures model, group means at individual timepoints were compared by $t$ test using a Bonferonni correction. The overall level of significance was set at $p<0.05$. Nonparametric data are presented as median value (range) and analyzed by Kruskal-Wallis, All other values are represented as mean \pm SD. P.V data for each animal were combined by group and pressure increment, then averaged and plotted. Volume was expressed per dry weight of the lung. $\mathrm{LV}_{\max }$ at $3.5 \mathrm{kPa}$ was used as a measure of the degree of total lung inflation. The degree of hysteresis was assessed by hysteresis area (comparing areas within the P-V loops) and deflation stability by the ratio of the deflation volume at $1.0 \mathrm{kPa}\left(\mathrm{V}_{1}\right)$ to $\mathrm{LV}_{\max }$, i.e. $\mathrm{V}_{1} / \mathrm{LV}_{\max }$. These parameters as well as volume at zero pressure $\left(V_{0}\right)$ were compared between groups using the unpaired $t$ test.

\section{RESULTS}

Physiologic data. Due to timed matings, the gestational age in both groups was $140 \pm 2 \mathrm{~d}$. Birth weights were not different between groups, being $0.511 \pm 0.046 \mathrm{~kg}$ in the HFOV and 0.502 $\pm 0.069 \mathrm{~kg}$ in the IMV animals. Two of seven HFOV and two of eight IMV animals were male. There were no significant intergroup differences in heart rate, mean arterial pressure, CVP, arterial $\mathrm{pH}$, or base deficit (Table 1). All seven HFOV and six of eight IMV animals survived the 24-h experimental period.

By design, initial $\overline{\mathrm{P}}_{\mathrm{aw}}$ was higher in the HFOV group at initiation of treatment and through $3 \mathrm{~h}$ of life $(p<0.006)$ (Fig. 1). However, there was no significant difference between the HFOV and IMV groups in initial $\mathrm{Pa} / \mathrm{AO}_{2}$. Arterial blood gas data at $30 \mathrm{~min}$ of age revealed $\mathrm{Pa} / \mathrm{AO}_{2}$ in the IMV animals to be $0.27 \pm 0.12$ compared with $0.31 \pm 0.17$ in the HFOV animals $(p=0.71)$. There was a significant time-related difference in $\overline{\mathrm{P}}_{\mathrm{aw}}$ between groups $(p<0.001)$. HFOV $\overline{\mathbf{P}}_{\mathrm{aw}}$ was progressively reduced during the study period in response to improved oxygenation as measured by $\mathrm{Pa} / \mathrm{AO}_{2}$ and to prevent lung overdistention as assessed by sequential chest radiographs. In contrast, it was necessary to increase $\overline{\mathrm{P}}_{\mathrm{aw}}$ in the IMV animals to maintain $\mathrm{Pa}$ / $\mathrm{AO}_{2}$. By $23 \mathrm{~h}$, the IMV group required higher $\overline{\mathrm{P}}_{\mathrm{aw}}(p<0.01)$ than the HFOV group, with significantly lower $\mathrm{Pa} / \mathrm{AO}_{2}(p<0.002)$. HFOV animals had indices of improved oxygenation at 3,8 , and $23 \mathrm{~h}$ : higher $\mathrm{Pa} / \mathrm{AO}_{2}(p<0.008)$ (Fig. 1) and lower $\mathrm{FiO}_{2}(p<$ 0.01 ) (Fig. 1).

Lung mechanics data. There were no significant differences in residual volume between the two ventilator groups. The P-V curve could not be generated for one IMV animal due to multiple antemortem airleaks. In the remaining animals, static $\mathrm{P}$-V curves revealed marked intergroup differences (Fig. 2). The HFOV animals had significantly increased lung volume at $\mathrm{LV}_{\max }$ and at $V_{1}$, but not at $V_{0}$ on the deflation limb. Hysteresis area was also significantly greater in the HFOV animals (Table 2). There was no difference in deflation stability as measured by $\left(\mathrm{V}_{1} / \mathrm{LV}_{\max }\right)$.

Microsphere results. There were no significant differences between the HFOV and IMV animals in LVO or $\dot{Q}_{s}$ eff at any of the timepoints studied (Fig. 3). Q ${ }_{s}$ eff is LVO minus the left to right PDA shunt, and thus equals the portion of LVO that contributes to systemic perfusion. At the 8-h timepoint IMV animals showed an apparent increase in LVO; however, due to greater systemic to pulmonary PDA shunting, $\dot{Q}_{s}$ eff was similar between groups.

There were no significant differences between groups in the fraction of LVO to the lungs (Fig. 4) or organ blood flow (Table 3 ) at each injection timepoint. Mean cerebral blood flow was less than $3.3 \mathrm{~mL} /(\mathrm{kg} \cdot \mathrm{s})$ at all timepoints studied.

Subgroup analysis. Three animals (two HFOV and one IMV) had severe cardiovascular depression with low cardiac output $[1.4 \pm 0.2 \mathrm{~mL} /(\mathrm{kg} \cdot \mathrm{s})$; normal, $3.5-4.0 \mathrm{~mL} /(\mathrm{kg} \cdot \mathrm{s})]$ severe metabolic acidosis $(-19.0 \pm 3.5 \mathrm{mmol} / \mathrm{L})$, and elevated CVP $(20.3 \pm$ $5.5 \mathrm{~mm} \mathrm{Hg}$ ) at $23 \mathrm{~h}$. Evidence of myocardial dysfunction was present in these animals as early as $3 \mathrm{~h}$ after delivery and persisted throughout the study period.

This subset of animals followed an atypical experimental course and potentially confounded the statistical analysis. We therefore analyzed the results excepting the above three animals (Table 4) and found no major changes in statistical significance of the variables when compared with the analysis performed using the entire group. However, the CVP between the two groups was more closely approximated when these three outliers were omitted.

\section{DISCUSSION}

There are relatively few studies in the literature concerning the cardiovascular effects of HFOV or of mechanical ventilation in general on immature subjects. Oguchi et al. (17) studied the hemodynamic effects of HFOV compared with IMV in preterm lamb after surfactant administration and ductus arteriosus occlusion. When HFOV was used at a $\overline{\mathrm{P}}_{\mathrm{aw}}$ similar to that of IMV, no significant differences were noted between the two groups in cardiac output, organ blood flow, or metabolic status. Similarly, 
Table 1. Mean arterial pressure $\left(B P_{m}\right), C V P$, arterial $p H$, and base deficit $(B D)$ for the IMV and HFOV animals at each injection

\begin{tabular}{cccccc}
\multicolumn{6}{c}{ timepoint $^{*}$} \\
Group/time (h) & $\begin{array}{c}\mathrm{BP}_{\mathrm{m}} \\
(\mathrm{kPa})\end{array}$ & $\begin{array}{c}\mathrm{CVP} \\
(\mathrm{mm} \mathrm{Hg})\end{array}$ & $\begin{array}{c}\mathrm{PaCO}_{2} \\
(\mathrm{kPa})\end{array}$ & $\begin{array}{c}\mathrm{pH} \\
(\mathrm{units})\end{array}$ & $\begin{array}{c}\mathrm{BD} \\
(\mathrm{mmol} / \mathrm{L})\end{array}$ \\
\hline IMV & & & & & \\
3 & $5.6 \pm 0.9$ & $3.0 \pm 1.2$ & $4.8 \pm 0.9$ & $7.25 \pm 0.08$ & $10.5 \pm 2.2$ \\
8 & $5.3 \pm 0.9$ & $4.6 \pm 4.3$ & $7.2 \pm 1.9$ & $7.12 \pm 0.12$ & $13.3 \pm 4.6$ \\
23 & $4.9 \pm 0.7$ & $6.2 \pm 7.0$ & $7.1 \pm 0.8$ & $7.12 \pm 0.09$ & $12.8 \pm 4.9$ \\
HFOV & & & & & \\
3 & $5.3 \pm 1.1$ & $5.8 \pm 3.3$ & $4.7 \pm 1.1$ & $7.27 \pm 0.10$ & $10.0 \pm 4.3$ \\
8 & $5.5 \pm 0.8$ & $6.9 \pm 5.3$ & $5.1 \pm 0.7$ & $7.21 \pm 0.06$ & $12.5 \pm 2.0$ \\
23 & $5.3 \pm 0.7$ & $8.7 \pm 8.8$ & $6.2 \pm 1.1$ & $7.13 \pm 0.13$ & $13.5 \pm 4.5$ \\
\hline
\end{tabular}

* There were no significant differences between the two groups. All values are mean \pm SD.
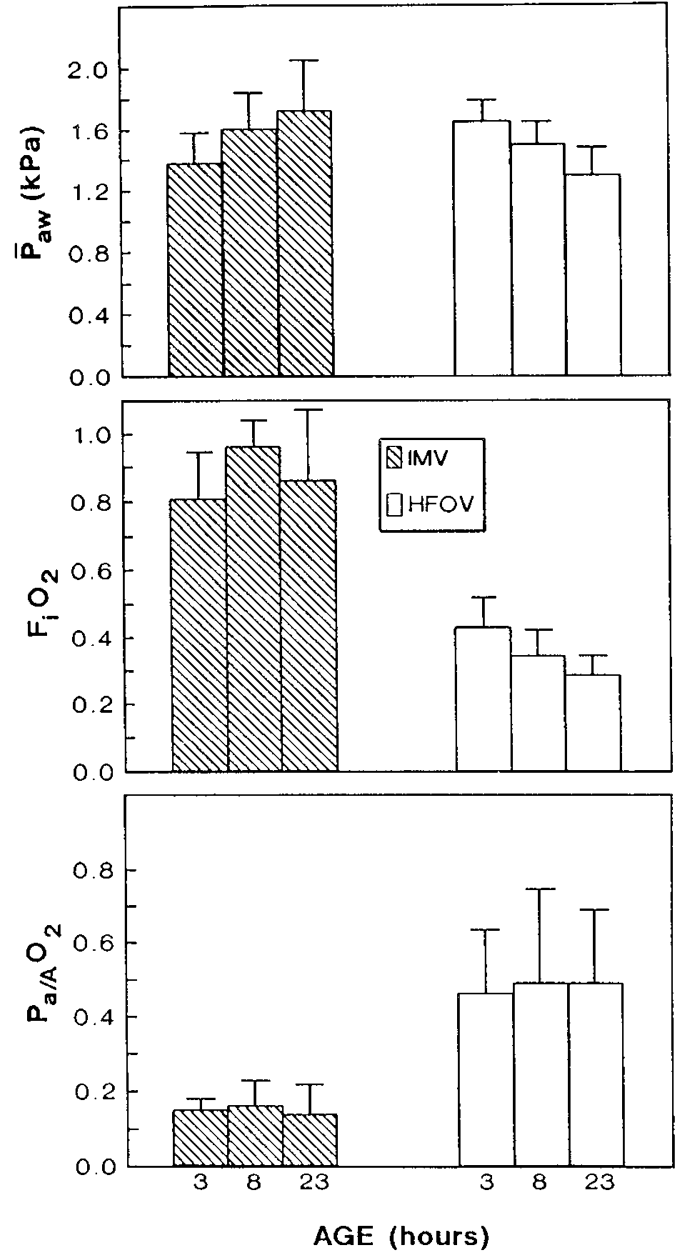

Fig. 1. $\overline{\mathrm{P}}_{\mathrm{aw}}, \mathrm{FiO}_{2}$, and $\mathrm{Pa} / \mathrm{AO}_{2}$ (mean $\pm \mathrm{SD}$ ) for IMV and $\mathrm{HFOV}$ animals at 3,8 , and $23 \mathrm{~h}$. Note that $\overline{\mathrm{P}}_{\mathrm{aw}}$ was initiated at a higher level with HFOV and reduced to a lower level by $23 \mathrm{~h}$.

Mirro et al. (18) found no significant intergroup differences in cardiac output or organ blood flow when comparing conventional ventilation with $\mathrm{HFOV}$ at similar mean $\overline{\mathrm{P}}_{\mathrm{aw}}(15 \mathrm{~cm} \mathrm{H} \mathrm{O})$ in surfactant-deficient rabbits. In a previous study using the premature baboon model, Meredith et al. (9) described dramatic improvement in gas exchange, lung mechanics, and lung morphology when HFOV was used at a high $\overline{\mathbf{P}}_{\mathrm{aw}}$ after an initial volume recruitment maneuver. However, the HFOV animals demonstrated indirect evidence of decreased cardiac output and systemic perfusion manifesting in metabolic acidosis by $8 \mathrm{~h}$ of age (9).

We had hypothesized that lung overinflation was the major factor leading to the presumed cardiovascular compromise in our previous studies using HFOV (9). Because $\overline{\mathrm{P}}_{\mathrm{aw}}$ is a controlled variable during HFOV, improved lung compliance would result

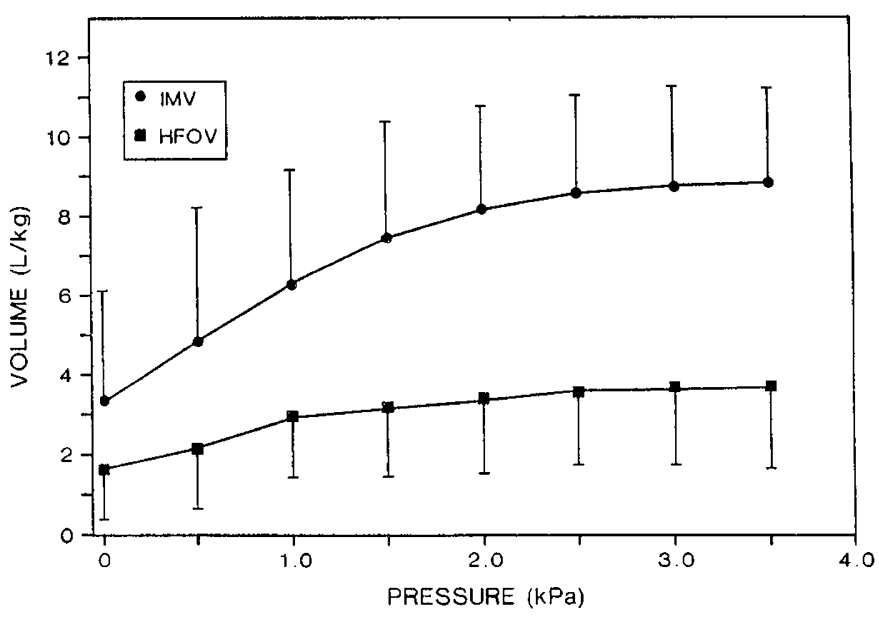

Fig. 2. Deflation limb of static volume pressure curves for the IMV and HFOV animals. One lung from the IMV group could not be studied due to multiple antemortem airleaks.

in increased lung volume at the same $\overline{\mathrm{P}}_{\mathrm{aw}}$. To replicate the beneficial pulmonary effects seen in our previous experiments while avoiding the adverse hemodynamic effects, we designed an HFOV strategy aimed at achieving early alveolar recruitment with high $\overline{\mathrm{P}}_{\mathrm{aw}}$ and subsequently reducing $\overline{\mathrm{P}}_{\mathrm{aw}}$ concomitant with improvement in oxygenation to prevent overinflation.

When we compared the results of this HFOV strategy with those of conventional mechanical ventilation in premature baboons with HMD, we found that the previously described improvements in oxygenation were achieved without adversely affecting hemodynamic status. It is important to stress, however, that optimal strategies are different for HFOV and IMV. To optimize the use of HFOV, early recruitment using high $\overline{\mathrm{P}}_{\mathrm{aw}}$ with rapid weaning concomitant with improvements in oxygenation is an essential component of the strategy. Although relatively high ventilator pressures were used in the IMV animals (initially $1.2-1.3 \mathrm{kPa} \overline{\mathrm{P}}_{\mathrm{aw}} ; 0.6-0.7 \mathrm{kPa}$ PEEP), previous studies in our laboratory have demonstrated that the initial use of $\overline{\mathrm{P}}_{\mathrm{aw}}$ that approach the levels used during HFOV lead to excessive air leaks (19).

In addition to marked differences in pressure requirements and oxygenation between ventilator groups over the study period, dramatic intergroup differences were present in the P-V curves at $24 \mathrm{~h}$. The lungs of the IMV animals exhibited decreased compliance and minimal hysteresis, similar to the findings of Gribetz et al. (20) in human premature infants with HMD and deLemos et al. (21) in premature lambs. Although there was no difference in deflation stability between IMV and HFOV groups, the lungs of the HFOV animals showed significantly higher $\mathrm{LV}_{\max }, \mathrm{V}_{1}$, and hysteresis. These intergroup differences in postmortem lung mechanics are similar to those previously reported by Meredith et al. (9) using the same model, and are felt to be related to the prevention of ventilator-induced lung injury. 
Table 2. $L V_{\max }(3.5 \mathrm{kPa})$ at $1.0 \mathrm{kPa}$ on deflation $\operatorname{limb}\left(V_{1}\right)$, at $0 \mathrm{kPa}$ on deflation limb $\left(V_{0}\right)$, hysteresis area, and $V_{1} / L V_{\max }(d e f l a$ stability) for IMV and HFOV animals

\begin{tabular}{cccccc}
\hline $\begin{array}{c}\text { Group } \\
(n)\end{array}$ & $\begin{array}{c}\mathrm{LV}_{\max } \\
(\mathrm{L} / \mathrm{kg})\end{array}$ & $\begin{array}{c}\mathrm{V}_{1} \\
(\mathrm{~L} / \mathrm{kg})\end{array}$ & $\begin{array}{c}\mathrm{V}_{0} \\
(\mathrm{~L} / \mathrm{kg})\end{array}$ & $\begin{array}{c}\text { Hysteresis area } \\
{[\mathrm{kPa} \cdot(\mathrm{L} / \mathrm{kg})]}\end{array}$ & $\mathrm{V}_{1} / \mathrm{LV} \mathrm{max}_{\max }$ \\
\hline IMV (7) & $3.70 \pm 2.09$ & $2.99 \pm 1.69$ & $1.63 \pm 1.36$ & $2.16 \pm 1.26$ & $0.70 \pm 0.12$ \\
HFOV $(7)$ & $8.74 \pm 2.63$ & $6.17 \pm 3.27$ & $3.32 \pm 2.96$ & $5.34 \pm 1.79$ & $0.64 \pm 0.19$ \\
Significance & $p=0.0019$ & $p=0.0405$ & $\mathrm{NS}$ & $p=0.0023$ & $\mathrm{NS}$ \\
\hline
\end{tabular}

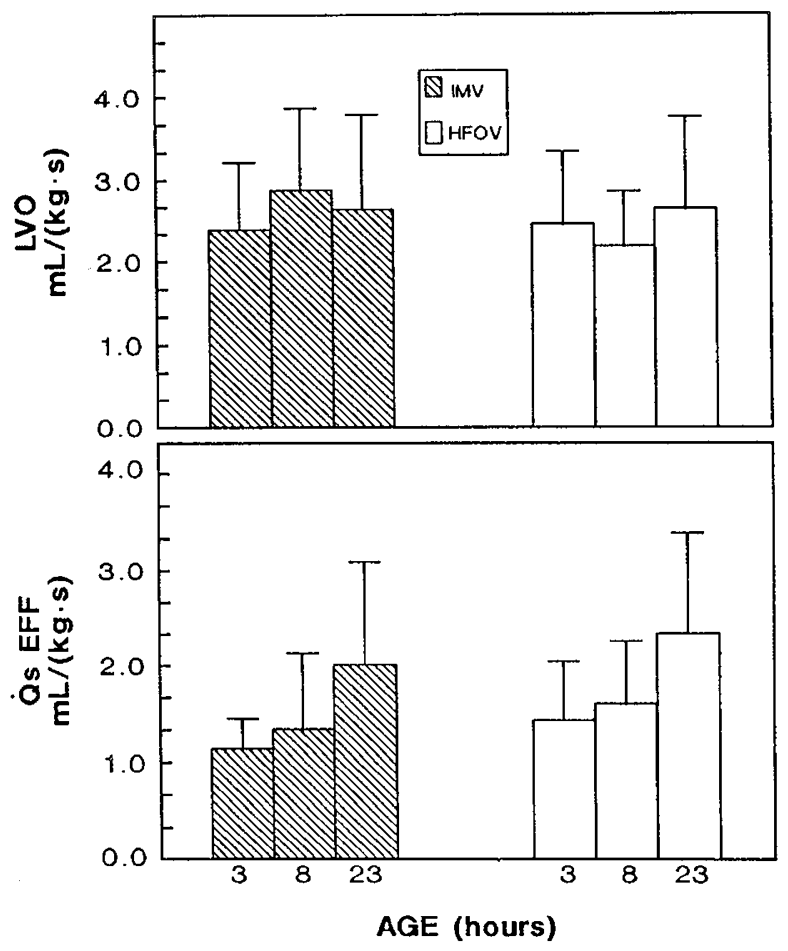

Fig. 3. LVO and $\dot{Q}_{s}$ eff for IMV and HFOV groups at 3, 8, and $23 \mathrm{~h}$. There were no significant differences between the two groups.

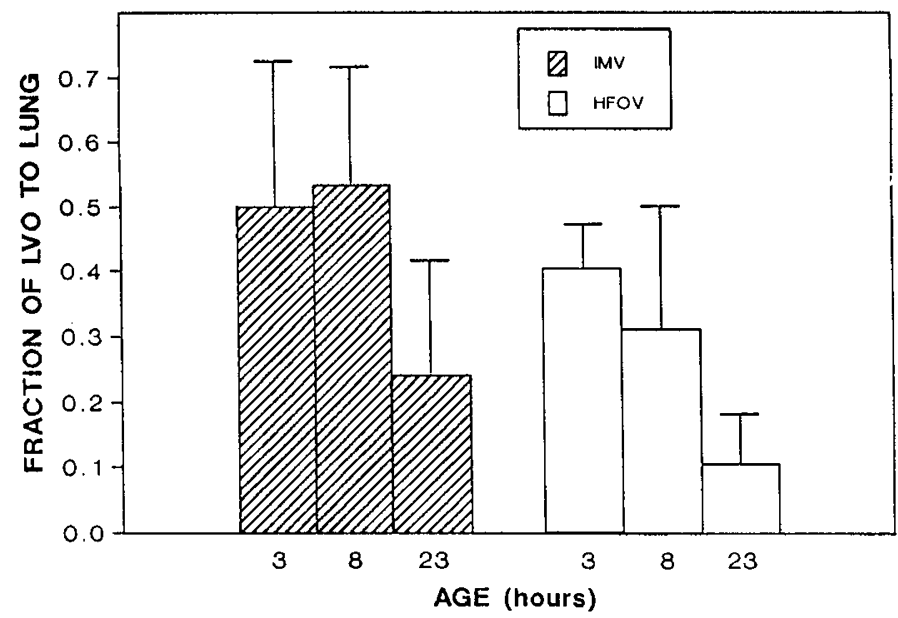

Fig. 4. Percent of LVO to lungs for IMV and HFOV groups at 3,8, and $23 \mathrm{~h}$. There were no significant differences between the two groups.

The possibility exists that an initial sigh maneuver might have altered the course of oxygenation during IMV treatment in this model. However, our clinical and laboratory impression is that such maneuvers in IMV animals do little to change the ongoing injury created by repeated tidal volume breathing in the absence of surfactant $(22,23)$. Moreover, Kolton et al. (24) studied the use of a sigh maneuver in oleic acid- and lung lavage-induced pulmonary injury in rabbits and found the sigh to be beneficial during HFOV at lower $\overline{\mathrm{P}}_{\mathrm{aw}}$, but not during IMV.

With the ventilator strategies used in this study, we found no significant differences in cardiac output or organ blood between the HFOV and IMV groups. However, it woulc inappropriate to assume that these values for cardiac output blood flow distribution represent "normal" cardiovascular $\mathrm{fi}$ tion in the premature baboon and that there were no adv effects of mechanical ventilation. One possible interpretatio these results is that hemodynamic effects were present and duced equally by both types of ventilation. Comparison wi nonventilated control group could not be made in the 16 premature baboon due to severe respiratory system immatu which necessitates mechanical ventilation even after surfac administration (deLemos RA, unpublished data).

In general, the results of our study are consistent with prev findings by other investigators. The adverse hemodynamic ef that occur during mechanical ventilation are less promis when lung compliance is low (25). Furthermore, it has $t$ recognized that hemodynamic stability may be preservec vigilant attention to reduction in airway pressure after impr ment in pulmonary compliance (26). Indeed, in the sem article on the use of CPAP in the human premature in Gregory et al. (27) found no substantial adverse hemodyne effects using CPAP up to $1.6 \mathrm{kPa}$. These authors concluded rapid reduction in CPAP concomitant with improvemen pulmonary compliance was essential to the safe use of therapy. Similarly, oxygenation improvement during HFO achieved through the application of a nearly constant $\overline{\mathrm{P}}_{\mathrm{aw}}$, careful attention to changes in compliance and lung volum crucial in adjusting $\overline{\mathrm{P}}_{\mathrm{aw}}$ to prevent cardiovascular embarrassm.

Although there are extensive fetal data on cardiac output organ blood flow in various species, there are limited data ir. premature baboon and in premature animals in general which to compare our findings. Paton et al. (28) studied b] flow distribution using microspheres in 150-160 d fetal babo Average combined ventricular output in their fetal model $4.7 \mathrm{~mL} /(\mathrm{kg} \cdot \mathrm{s})$. Renal and cerebral blood flow were 27.71 $(\mathrm{kg} \cdot \mathrm{s})$ and $5.5 \mathrm{~mL} /(\mathrm{kg} \cdot \mathrm{s})$, respectively. They noted that $\mathrm{b}$ blood flow per unit weight of tissue was considerably less 1 that reported for fetal rhesus monkeys and sheep at near-t gestation. Given the limited cardiovascular reserve of imma subjects and systemic to pulmonary shunting across a PDA were not surprised to find somewhat lower renal and cere blood flow in the 140-d premature baboon. Moreover, stu on the ontogeny of regional brain blood flow distribution ir lamb have demonstrated that cerebral flow is lower in the term fetus compared with more mature animals (29). Inte ingly, the average cerebral blood flow for premature babr that we measured during the first day of life $[2.7 \mathrm{~mL} /(\mathrm{kg} \cdot \mathrm{s})]$ very similar to that reported by Greisen (30) in human prema infants using the xenon clearance technique $[2.6 \mathrm{~mL} /(\mathrm{kg} \cdot \mathrm{s})$.

An unexpected finding during our study was the presenc severe myocardial dysfunction in three animals. These ani (one IMV and two HFOV) showed low cardiac output, se metabolic acidosis, and markedly elevated CVP, consistent myocardial failure. Although not significantly different, the vated CVP in these two HFOV animals accounted for the sliq higher mean CVP values in the HFOV group. Evidenc myocardial dysfunction was present as early as $3 \mathrm{~h}$ after deli and persisted through the study period, suggesting failure of fetal myocardium to transition to meet extrauterine dema These data implicate factors distinct from underlying lung dis or mode of ventilation as the cause for failure of fetal myoca 
Table 3. $\dot{Q}_{s}$ eff and organ blood flow for IMV and HFOV animals*

\begin{tabular}{|c|c|c|c|c|c|c|}
\hline $\begin{array}{l}\text { Time } \\
\text { (h) }\end{array}$ & Group & $\dot{\mathrm{Q}}_{\mathrm{s}} \mathrm{eff}$ & Cerebral & Renal & Small intestine & $\begin{array}{c}\text { Large } \\
\text { intestine }\end{array}$ \\
\hline \multirow[t]{2}{*}{3} & IMV & $1.14 \pm 0.32$ & $1.8(1.2-2.5)$ & $15.0(6.7-34.2)$ & $7.2(1.8-30.7)$ & $1.7(0.8-17.8)$ \\
\hline & $\mathrm{HFOV}$ & $1.44 \pm 0.62$ & $2.5(0.7-4.7)$ & $19.3(13.8-24.5)$ & $14.8(7.0-25.2)$ & $2.0(1.3-5.0)$ \\
\hline 8 & HFOV & $1.60 \pm 0.66$ & $2.2(0.7-5.7)$ & $17.3(9.5-24.2)$ & $8.2(6.2-13.3)$ & $1.7(1.2-2.8)$ \\
\hline \multirow[t]{2}{*}{23} & IMV & $2.01 \pm 1.08$ & $2.7(1.5-5.3)$ & $14.3(3.5-18.8)$ & $10.7(4.3-15.7)$ & $2.7(1.0-15.7)$ \\
\hline & HFOV & $2.20 \pm 1.07$ & $2.5(0.5-6.7)$ & A3 $(3.5-20.5)$ & $13.7(6.5-25.0)$ & $2.2(1.0-3.0)$ \\
\hline
\end{tabular}

* Values are $\mathrm{mL} /(\mathrm{kg} \cdot \mathrm{s})$ for $\dot{\mathrm{Q}}_{\mathrm{s}}$ eff and organ blood flow. Values represented as mean $\pm \mathrm{SD}$ for $\dot{\mathrm{Q}}_{\mathrm{s}} \mathrm{eff}$ and median (range) for organ blood flow.

Table 4. Hemodynamic status of a subset of animals with stable cardiac status (seven IMV, five HFOV)*

\begin{tabular}{rccc}
\hline & $\begin{array}{c}\mathrm{LVO} \\
{[\mathrm{mL} /(\mathrm{kg} \cdot \mathrm{s})]}\end{array}$ & $\begin{array}{c}\mathrm{CVP} \\
(\mathrm{mm} \mathrm{Hg})\end{array}$ & $\begin{array}{c}\text { Base deficit } \\
(\mathrm{mmol} / \mathrm{L})\end{array}$ \\
\hline $\mathrm{IMV}$ & & & \\
$3 \mathrm{~h}$ & $2.45 \pm 0.80$ & $2.7 \pm 1.0$ & $10.6 \pm 2.4$ \\
$8 \mathrm{~h}$ & $2.98 \pm 0.93$ & $3.0 \pm 1.3$ & $12.0 \pm 3.3$ \\
$23 \mathrm{~h}$ & $2.90 \pm 1.12$ & $3.6 \pm 1.9$ & $11.2 \pm 3.1$ \\
$\mathrm{HFOV}$ & & & \\
$3 \mathrm{~h}$ & $2.65 \pm 0.83$ & $4.5 \pm 2.4$ & $10.8 \pm 4.6$ \\
$8 \mathrm{~h}$ & $2.38 \pm 0.67$ & $4.6 \pm 2.2$ & $12.2 \pm 1.1$ \\
$23 \mathrm{~h}$ & $3.07 \pm 0.93$ & $4.0 \pm 1.9$ & $11.6 \pm 3.3$ \\
\hline
\end{tabular}

* Values are mean $\pm \mathrm{SD}$.

adaptation. We have previously described marked changes in left ventricular function between $\mathrm{d} 1$ and 3 of life in the premature baboon (31) that are associated with improvement in pulmonary and renal function (32). Moreover, induction of $\alpha$-myosin heavychain synthesis in ventricular myocardium of premature baboons has been demonstrated to occur over the first $10 \mathrm{~d}$ of life (33). Other investigators have identified altered left ventricular diastolic function (34), and decreased troponin T isoform expression (35) as contributory to myocardial dysfunction in the neonatal period. Studies are now in progress in our laboratories to characterize myocardial adaptation and function in the premature baboon.

We have demonstrated that modifications in strategy used during HFOV can result in sustained improvement in oxygenation, without adversely affecting cardiac output and organ blood flow, compared with IMV in the premature baboon. However, we stress that the apparent predisposition of the premature infant to myocardial dysfunction requires careful assessment of potential cardiopulmonary interactions to prevent hemodynamic compromise during HFOV. The strategy we used was specifically designed to achieve early alveolar recruitment, and when followed by improving oxygenation, a rapid reduction in $\overline{\mathrm{P}}_{\mathrm{aw}}$ to prevent lung overdistention. During HFOV, strategies that do not carefully account for progressive increases in lung volume and compliance after alveolar recruitment are inappropriate for the premature infant. Lung overdistention may allow for excessive transmission of airway pressure to the pleural space, impeding venous return and diminishing cardiac output. Both of these factors may predispose to both intracranial hemorrhage and ischemic injury to the brain of the premature infant (6).

\section{CONCLUSION}

With the strategy used in this study, HFOV resulted in significant improvement in oxygenation compared with conventional mechanical ventilation. Cardiac output, CVP, and organ blood flow were not significantly different between groups over the 24h experiment.

The interaction of airway pressure with cardiac output and organ blood flow is intimately related to lung compliance and lung volume in HMD. Thus, the effective and safe use of HFOV requires careful adjustment of ventilator settings paralleling changes in oxygenation. High airway pressures may be used to recruit atelectatic lung without attendant hemodynamic compromise when lung volumes and compliance are low. However, the potential for transmission of airway pressure in the recovering lung must be closely monitored. HFOV must be used with caution in the extremely premature infant at greatest risk from the adverse effects of lung overdistention. Finally, failure of cardiovascular adaptation may be a limiting factor in the successful application of any technique designed to ameliorate premature lung disease.

Acknowledgments. The authors thank Drs. J. I. E. Hoffman, D. F. Teitel, and B. D. Payne for helpful suggestions concerning microsphere methodology.

\section{REFERENCES}

1. Bryan AC 1989 Summary: clinical aspects of HFV (I). Acta Anaesthesiol Scand 33(suppl 90):176

2. Froese AB 1989 Role of lung volume in lung injury: HFO in the atelectasisprone lung. Acta Anaesthesiol Scand 33(suppl 90):126-130

3. deLemos J, Dryer G, Gerstmann D, deLemos R 1989 Oliguria in the premature baboon with hyaline membrane disease: a manifestation of multisystem immaturity? J Perinatol 9:19-25

4. Froese AB, Butler PO, Fletcher WA, Byford LJ 1987 High-frequency oscillatory ventilation in premature infants with respiratory failure: a preliminary report. Anesth Analg 66:814-824

5. Hamilton PP, Onayemi A, Smyth JA, Gillan JE, Cutz E, Froese AB, Bryan AC 1983 Comparison of conventional and high-frequency ventilation: oxygenation and lung pathology. J Appl Physiol Respir Environ Exercise Physiol 55:131-138

6. HIFI Study Group 1989 High-frequency oscillatory ventilation compared with conventional mechanical ventilation in the treatment of respiratory failure in preterm infants. N Engl J Med 320:88-93

7. Truog WE, Standaert TA, Murphy J, Palmer S, Woodrum DE, Hodson WA 1983 Effect of high-frequency oscillation on gas exchange and pulmonary phospholipids in experimental hyaline membrane disease. Am Rev Respir Dis 127:585-599

8. Truog WE, Standaert TA, Murphy JH, Woodrum DE, Hodson WA 1984 Effects of prolonged high-frequency oscillatory ventilation in premature primates with experimental hyaline membrane disease. Am Rev Respir Dis $130: 76-80$

9. Meredith KS, deLemos RA, Coalson JJ, King RJ, Gerstmann DR, Kumar R, Kuehl TJ, Winter DC, Taylor A, Clark RH, Null Jr DM 1989 Role of lung injury in the pathogenesis of hyaline membrane disease in premature baboons. J Appl Physiol 66:2150-2158

10. Traverse JH, Korvenranta H, Adams EM, Goldthwait DA, Carlo WA 1988 Impairment of hemodynamics with increasing mean airway pressure during high-frequency oscillatory ventilation. Pediatr Res 23:628-631

11. Venas B, Cohen LE, Smith RA 1988 Hemodynamics and intrathoracic pressure transmission during controlled mechanical ventilation and positive endexpiratory pressure in normal and low compliant lungs. Crit Care Med 16:686-690

12. Wagner PD 1989 Summary: HFV and pulmonary physiology. Acta Anaesthesiol Scand 33(suppl 90):172-175

13. Bell RE, Kuehl TJ, Coalson JJ, Ackerman Jr NB, Null Jr DM, Escobedo MB, Yoder GA, Cornish JD, Nalle L, Skarin RM, Cipriani CA, Montes M, Robotham JL, deLemos RA 1984 High-frequency ventilation compared to conventional positive-pressure ventilation in the treatment of hyaline membrane disease in primates. Crit Care Med 12:764-768

14. Heymann MA, Payne BD, Hoffman JIE, Rudolph AM 1977 Blood flow measurements with radionuclide-labeled particles. Prog Cardiovasc Dis 20:55-79

15. Buckberg GD, Luck JC, Payne DB, Hoffman JIE, Archie JP, Fixler DE 1971 Some sources of error in measuring regional blood flow with radioactive microspheres, J Appl Physiol 31:598-604

16. Hoffman JIE, Payne BD, Heymann MA, Rudolph AM 1983 The use of microspheres to measure blood flow. Tech Life Sci P3/1:1-36

17. Oguchi K, Baylen BG, Ikegami M, Jacobs H, Berry D, Jobe A, Emmanouilides 
GC 1986 Hemodynamic effects of high-frequency ventilation in surfactanttreated preterm lambs. Biol Neonate 49:21-28

18. Mirro R, Tamura M, Kawano T 1985 Systemic cardiac output and distribution during high-frequency oscillation. Crit Care Med 13:724-727

19. Gerstmann, DR, delemos RA, Coalson JJ, Clark RH, Wiswell TE, Winter DC, Kuehl TJ, Meredith KS, Null Jr DM 1988 Influence of ventilatory technique on pulmonary baroinjury in baboons with hyaline membrane disease. Pediatr Pulmonol 5:82-91

20. Gribetz I, Frank NR, Avery ME 1959 Static volume-pressure relations of excised lungs of infants with hyaline membrane disease, newborn and stillborn infants. $\mathbf{J}$ Clin Invest 38:2168-2175

21. deLemos RA, Coalson JJ, Gerstmann DR, Null Jr DM, Ackerman NB, Escobedo MB, Robotham JL, Kuehl TJ 1987 Ventilatory management of infant baboons with hyaline membrane disease: the use of high-frequency ventilation. Pediatr Res 21:594-602

22. Solca M, Kuehl TJ, Frigerio L, Farina C, Coalson JJ, deLemos RA 1988 Lung conditioning in premature fetal baboon. Pediatr Res 23(4, Pt 2):525A(abstr)

23. deLemos RA, Coalson JJ, Meredith KS, Gerstmann DR, Null Jr DM 1989 A comparison of ventilation strategies for the use of high-frequency oscillatory ventilation in the treatment of hyaline membrane disease. Acta Anaesthesio Scand 33(suppl 90):102-107

24. Kolton M, Cattran CB, Kent G, Volgyesi G, Froese AB, Bryan AC 1982 Oxygenation during high-frequency ventilation compared with conventional mechanical ventilation in two models of lung injury. Anesth Analg 61:323332

25. Mirro R, Busija D, Green R, Leffler C 1987 Relationship between mean airway pressure, cardiac output, and organ blood flow with normal and decreased respiratory compliance. J Pediatr 111:101-106
26. Gregory GA 1986 Continuous positive airway pressure. In: Thibeault DW Gregory GA (eds) Neonatal Pulmonary Care, 2nd Ed. Appleton-CenturyCrofts, Norwalk, CT, p 357

27. Gregory GA, Kitterman JA, Phibbs RH, Tooley WH, Hamilton WK 197 Treatment of the idiopathic respiratory-distress syndrome with continuous positive airway pressure. N Engl J Med 284:1333-1340

28. Paton JB, Fisher DE, Peterson EN, deLannoy CW, Behrman RE 1973 Cardia output and organ blood flows in the baboon fetus. Biol Neonate 22:50-57

29. Szymonowicz W, Walker AM, Cussen L, Cannata J, Yu VYH 1988 Developmental changes in regional cerebral blood flow in fetal and newborn lambs. Am J Physiol 254:H52-H58

30. Greisen G 1986 Cerebral blood flow in preterm infants during the first week of life. Acta Pediatr Scand 75:43-51

31. Morrow WR, Taylor F, Gerstmann DR, McCurnin DC, deLemos RA 1988 Hemodynamics of patent ductus arteriosus in preterm baboons with HMD. Pediatr Res 23:419A(abstr)

32. DeLemos RA, Shermeta DW, Knelson JH, Kotas R, Avery ME 1970 Acceleration of appearance of pulmonary surfactant in the fetal lamb by administration of corticosteroids. Am Rev Respir Dis 102:459-461

33. Hixson JE, Henkel RD, Britten JL, Vernier DT, deLemos RA, VandeBerg JL, Walsh RA 1989 Alpha-myosin heavy chain DNA structure and gene expression in adult, fetal, and premature baboons myocardium. J Mol Cell Cardiol 21:1073-1086

34. Anderson PAW, Moore GE, Nassar RN 1988 Developmental changes in the expression of rabbit left ventricular troponin T. Circ Res 63:742-747

35. Appleton RS, Graham Jr TP, Cotton RB, Moreau GA, Boucek Jr RJ 1987 Altered early left ventricular diastolic cardiac function in the premature infant. Am J Cardiol 59:1391-1394 